\title{
Crises econômicas e os arranjos na burocracia da administração pública brasileira
}

\section{Economic crises and arrangements in the brazilian public administration of bureaucracy}

\author{
José Maria Ramos* \\ Oksandro Odisval Gonçalves**
}

\section{Resumo}

Crises são inerentes ao sistema capitalista e impõem a necessidade de ajustes no âmbito econômico, social ou político. As duas últimas crises que afetaram significativamente a economia brasileira exigiram medidas diversas. A primeira crise, iniciada ainda no final da década de 1970, redefiniu o papel do Estado na economia com a reforma do Estado e a reforma da administração pública. $\mathrm{Na}$ crise econômico-financeira de 2008, considerada a mais significativa desde a crise de 1929, as medidas tomadas para enfrentá-la diferem da crise anterior: houve um aumento da intervenção do Estado com objetivos de estimular o crescimento econômico, porém simultaneamente, dada a escassez de recursos para investimentos, a política de concessão de serviços públicos continuou, principalmente em infraestrutura de transportes. Embora medidas tenham sido

Professor Assistente da Universidade Estadual do Oeste do Paraná (Unioeste). Economista, bacharel em Direito, mestre em Análise Regional e doutorando em Direito no Programa de PósGraduação em Direito da Universidade Pontifícia Católica do Paraná (PUCPR). Curitiba - PR - Brasil. E-mail: jmramoseco@hotmail.com.

* Professor do Programa de Pós-Graduação em Direito (Mestrado/Doutorado) da Pontifícia Universidade Católica do Paraná. Professor de Direito Comercial da Escola de Direito da Pontifícia Universidade Católica do Paraná. Professor de Direito Empresarial do Curso de Especialização em Direito Civil e Empresarial da Pontifícia Universidade Católica do Paraná. Membro do Conselho Editorial da Editora Fórum. Coordenador da Revista de Direito Empresarial. Doutor em Direito Comercial pela Pontifícia Universidade Católica de São Paulo. Mestre em Direito Econômico pela Pontifícia Universidade Católica do Paraná. Advogado. Bolsista CAPES processo n. BEX 049016-4. CAPES Foundation, Ministry of Education of Brazil, Brasília/DF 70040-020, Curitiba PR -Brasil. E-mail: oksandro@cgaadv.com.br. 
tomadas para mitigar os reflexos da crise, não houve avanços importantes para reduzir a burocracia do Estado de forma a consolidar uma administração pública gerencial.

Palavras-chave: Administração pública. Crises econômicas. Burocracia. Intervenção do Estado. Desenvolvimento.

\section{Abstract}

Crises are inherent to the capitalist system, crisis impose the need for adjustments to be in economic, social or political sphere. The last two most significant crises which affected the Brazilian economy demanded a wide variety of measures. The first crisis begun, still, at the end of the 1970s redefined the role of the state in the economy - with state reform and public administration reform. The economic and financial crisis of 2008, considered the most significant since the 1929 crisis, the measures taken to counter it differ from the previous crisis, there was an increase in state intervention with aims to stimulate economic growth, however at the same time given the scarcity resources for investments, the public service concession policy continued, particularly in transport infrastructure. Although measures have been taken to mitigate the effects of the crisis, there was no significant progress to reduce the bureaucracy of the State in order to consolidate a managerial public administration.

Keywords: Public administration. Economic crises. Bureaucracy. State intervention. Development

\section{Introdução}

Os Estados, os modelos político-econômicos e as formas administrativas organizacionais passam por crises, que são inerentes às transformações políticas, econômicas-e sociais de cada época, as quais são recorrentes e trazem mudanças não apenas nos âmbitos da ordem econômica, social e política, mas também no modelo de organização burocrática do Estado. As principais mudanças do modelo de organização administrativa burocrática do Estado brasileiro decorreram de momentos de crise econômica ou política, ou de ambas simultaneamente, e as medidas adotadas como solução, geralmente 
levam a uma maior ou menor intervenção do Estado sobre o domínio econômico, a depender da ideologia do governo do momento.

A crise brasileira ocorrida no final dos anos de 1970, que se estendeu até meados da década de 1990, marcou um período em que o Estado perdeu sua capacidade de investimento. Assim, foi necessário implementar medidas para o fortalecimento do Estado e a reorganização burocrática da administração pública, o que culminou com o Plano Diretor da Reforma do Aparelho do Estado ${ }^{1}$ de 1995, por força do qual foram promovidas alterações na Constituição por meio da Emenda $n^{\circ}$ 19, além de políticas econômicas de caráter restritivo. Essas medidas estão associadas ao Plano Real, editado em 1994, que promoveu um período de estabilidade econômica especialmente relevante.

Em 2008, a crise financeira internacional, iniciada nos Estados Unidos, atingiu todos os países em alguma medida, afetando o sistema financeiro e as atividades produtivas. No Brasil, o governo adotou um conjunto de medidas anticíclicas com o intuito de recuperar a capacidade de investimento e manter o ritmo de crescimento. Em um primeiro momento, adotou medidas de incentivo ao consumo e políticas de fortalecimento de atividades industriais previamente selecionadas, como a Política de Desenvolvimento Produtivo ${ }^{2}$. Contudo, com a persistência da situação de crise e o esgotamento do modelo de incentivos, associado à perda de capacidade de investimentos em setores estratégicos, o governo tardiamente passou a estimular, ainda que de forma lenta, programas de concessão de serviços públicos, notadamente em portos,

1 O Plano Diretor da Reforma do Aparelho do Estado tomou como base as experiências dos países da OCDE, principalmente o Reino Unido, onde se implantava a segunda grande reforma administrativa da história do capitalismo: depois da reforma burocrática do século XIX, a reforma gerencial do final século $X X$. A reforma gerencial só é possível com um quadro de funcionários públicos de alto nível, com capacidade de mandato legal (BRESSER-PEREIRA, 1998a).

2 A Política de Desenvolvimento Produtivo foi estruturada em três programas: Programas mobilizadores em áreas estratégicas, como Complexo Industrial da Saúde; Tecnologias de Informação e Comunicação; Energia Nuclear; Complexo Industrial de Defesa; e Nanotecnologia e Biotecnologia. É um programa para consolidar e expandir a liderança no Complexo aeronáutico; Petróleo, gás e petroquímica; Bioetanol, mineração e siderurgia; Celulose e papel; e Carnes. Ao mesmo tempo, é um programa para fortalecer a competitividade em setores como: automotivo, têxtil e de confecções; indústria naval e cabotagem; e as agroindústrias. 
aeroportos e rodovias, reduzindo a interferência estatal com vistas a captar novos investimentos e melhorar a competitividade brasileira.

As situações de crise indicam a necessidade de medidas para o fortalecimento do Estado e uma reorganização do seu modo de intervenção, tanto na economia quanto na organização burocrática estatal, para torná-la mais eficiente e gerencial. Com essas considerações, questiona-se: como as crises econômicas afetam a organização burocrática administrativa brasileira? As crises enfrentadas na economia brasileira contribuíram para uma melhor administração burocrática do Estado? Neste sentido, o artigo tem como objetivo analisar os reflexos das crises que afetaram a dinâmica econômica brasileira sobre a organização burocrática estatal, em especial na forma de intervenção do Estado na economia. Para cumprir com o objetivo proposto, fez-se uma pesquisa bibliográfica sobre as crises dos anos de 1980 ea crise econômico-financeira de 2008, assim como de seus reflexos sobre o comportamento da administração burocrática brasileira.

O texto está estruturado em quatro partes, além desta introdução. Após apresentar algumas características da burocracia a partir da concepção weberiana, a segunda parte aborda a reforma do Estado a partir da crise dos anos de 1980, e a terceira trata das medidas econômicas e políticas tomadas no ambiente da crise financeira de 2008. Por fim, as considerações finais.

\section{As características da burocracia weberiana}

O termo burocracia remete à ideia de administração racional e eficiente, ou o seu contrário, cujas raízes, segundo Max Weber (1999), surgem das relações de poder, legitimidade, estrutura organizacional e funcionamento, a partir de um quadro de funcionários submetidos a normas de conduta. Embora a burocracia não tenha um conceito preciso, ninguém dela escapa, tanto que é estudada na sociologia política, na teoria da história e da opinião pública (LEFORT, 1979). É um tema recorrente em momentos de crise econômica, principalmente 
quando exigem mudanças no sentido de ampliar ou reduzir o tamanho da presença do Estado no âmbito da economia.

Na perspectiva da teoria marxista, a burocracia é uma estrutura da administração dos negócios públicos em uma sociedade de classes que "normalmente" está a serviço da classe dominante, pois a burocracia "atribui ao Estado seus próprios objetivos, que são os de manter a divisão social para confirmar e justificar seu estatuto próprio de corpo particular e privilegiado na sociedade" (LEFORT, 1979, p. 151). Nessa percepção, a burocracia é um fenômeno parasitário. Essa concepção, contudo, é insuficiente, em razão da necessidade de uma maior participação do Estado em atividades econômicas, quer de forma direta, quer indireta, bem como na orientação de investimentos a partir da política econômica (monetária, fiscal ou cambial) de um determinado governo, principalmente quando há situação de crise econômica.

A burocracia é uma estrutura necessária na sociedade moderna, principalmente em uma sociedade capitalista, e, por isso, passa a ser compreendida como um tipo de organização racional que, na visão weberiana, encontra razão por ter uma "superioridade puramente técnica sobre qualquer outra forma de organização” (GERTH; MILLS, 1946, p. 249). O modelo de burocracia desenvolvido por Weber se pautava em um Estado liberal europeu, cujos principais parâmetros de organização de sua época encontravam-se na Igreja e no Exército. Para Cohn (2003, p. 14), tanto é assim que na obra "Condições Agrárias da Antiguidade", de 1909, Max Weber já indicava a possibilidade da burocracia "assenhorear-se do capitalismo", no sentido de organização e racionalidade.

As características da burocracia moderna no sistema capitalista, segundo Max Weber, são: 1) as atribuições dos funcionários são oficialmente fixadas por força de leis, de normas ou de disposições administrativas; 2) hierarquização das funções, com uma supervisão dos postos inferiores pelos superiores, mas com a possibilidade de apelar para uma instância superior de decisões das instâncias inferiores; 3) a atividade administrativa é registrada em documentos escritos; 4) a administração burocrática exige uma especialização das funções e 
constante treinamento; 5) é exigida do funcionário uma dedicação plena ao cargo ocupado; 6) o cargo exige desempenho com regras gerais e com aprendizado técnico especial, conforme área de atuação (GERTH; MILLS, 1946, p. 229-231).

Essas características tornam a burocracia uma estrutura necessária para a organização das economias capitalistas, que considera a "precisão, velocidade, clareza, conhecimento dos arquivos, continuidade, discrição [e] subordinação rigorosa", com o fim de conduzir ao ponto ótimo uma organização rigorosamente burocrática (GERTH; MILLS, 1946, p. 249). Max Weber (1999) trata a burocracia como uma estrutura racional-legal e como uma forma de dominação legal, que se apóia sobre o conhecimento técnico, a qualificação profissional e a especialização, separando o trabalhador dos meios de produção, o que confere a burocracia um caráter objetivo e racional, e a transforma em um instrumento para eficiência administrativa. Nesse sentido, a burocracia não representa obstáculos, mas sim instrumentos do Estado na promoção do desenvolvimento.

O modelo de administração pública burocrática, pautado no controle do Estado por leis, regulações e rotinas severas surgiu, segundo Bresser-Pereira (1998b, p. 9), quando a democracia dava os primeiros passos no século XIX, momento em que havia uma desconfiança mútua entre servidores, políticos e cidadãos. Mas, com a maturidade cultural e política, pressupõe-se que o "patrimonialismo está condenado, e o burocratismo está excluído, porque é ineficiente, sendo assim possível desenvolver estratégias administrativas baseadas na ampla delegação de autoridade e na cobrança a posteriori de resultados", ou seja, um Estado com administração gerencial.

A burocracia, segundo Gabardo (2009, p. 114), é "essencialmente metapragmático". A adoção da impessoalidade como princípio fundamental, a separação do patrimônio público do privado e a dissociação da esfera pública da administrativa são os pressupostos da burocracia, que são alcançados "pela manutenção da hierarquia e unidade de comando, além de certa rigidez nas rotinas e procedimentos". 
Em relação à estrutura da burocracia brasileira, Diniz (2001, p. 20) afirma que nunca houve uma burocracia propriamente weberiana, mas "um sistema marcado pela coexistência dos princípios universalistas e meritocráticos, com as práticas clientelistas, tradicionalmente presentes no padrão de expansão da burocracia brasileira". A burocracia é, em partes, um reflexo da cultura do país, na sua forma de construir e desenvolver as relações públicas e privadas. Nesse sentido, BresserPereira (1998a, p. 52) destaca que, embora a reforma gerencial tenha conquistado uma projeção mundial, "seu impacto é altamente variável, dependendo da história, cultura e lideranças políticas e administrativas dos diversos países". Michel Crozier (1981) também aponta que as relações humanas que constituem o tecido dos sistemas de ação (sistema educacional, sistema político-administrativo, sistema de empresas e outros) são determinadas por traços culturais do sistema burocrático de organização, que são interdependentes, mas que, ao mesmo tempo, se reforçam mutuamente.

Após traçar algumas das características sobre o fenômeno da burocracia, passa-se a analisar como crises econômicas da década de 1980 e a crise econômico-financeira de 2008 afetaram a estrutura da administração pública burocrática brasileira.

\section{A crise econômica como causa da reforma do estado}

As transformações no modelo burocrático brasileiro decorreram de momentos de crise política e/ou econômica. A primeira reforma ocorreu em 1936, no governo de Getúlio Vargas (1930-1945), após a vitória na Revolução de 1930, em que se promoveu a substituição do modelo patrimonialista para um modelo de burocracia clássica. A segunda reforma foi introduzida durante o período da ditadura militar, sendo considerada por Bresser-Pereira (1998c, p. 51) como um primeiro momento da administração gerencial no Brasil,

com a transferência das atividades de produção de bens e serviços para autarquias, fundações, empresas públicas e sociedades de economia mista, com objetivos da racionalidade administrativa e controle de resultados, uma reforma desenvolvimentista segundo o autor. 
Com o fim da ditadura militar, o período a partir de 1985, na análise histórica do Brasil, marca o início da Nova República, que já surge em um momento de crise que afeta a dinâmica econômica e política, e a burocracia do Estado. O campo econômico foi marcado pela perda de capacidade de intervenção do Estado na promoção do desenvolvimento econômico e social decorrente da crise fiscal. A crise política estava relacionada ao próprio golpe militar de 1964, ao fracasso e instabilidade provocados pelos planos econômicos de controle da inflação na década de 1980 e ao impeachment de Fernando Collor de Mello em 1991. Para Bresser-Pereira (1998c), a crise da administração pública burocrática começou ainda no regime militar, que não logrou êxito em eliminar o patrimonialismo e tampouco consolidou uma burocracia profissional.

A crise do Estado e da administração pública burocrática mostrou a necessidade de reformas econômicas e institucionais, as quais levaram o país a um processo de privatização, abertura comercial e reforma tributária e previdenciária na década de 1990. Para Bresser-Pereira (1998a, p. 33), "a crise do Estado impôs a necessidade de reconstruílo, a globalização o imperativo de redefinir suas funções”, enquanto a crise fiscal exigiu mudanças no modo de intervenção do Estado no campo econômico e social, bem como a necessidade de reformar sua administração burocrática.

As medidas para enfrentar a crise podem ser divididas em dois momentos. O primeiro, decorrente da crise fiscal do Estado, envolve um conjunto de medidas estruturais e de reforma. Medidas estruturais tratam do ajuste fiscal, com vistas a proporcionar um superávit primário da liberalização comercial e liberalização de preços controlados pelo Estado. Os programas de privatização se enquadram como reforma do Estado, com objetivo ilusório de um Estado mínimo neoliberal, de acordo com Bresser-Pereira (1998a). O segundo momento ocorre a partir da segunda metade dos anos de 1990, com a reforma gerencial e aplicação de novos princípios e práticas na gestão pública, cujo objetivo é reconstruir a capacidade do Estado em termos fiscais e de legitimidade democrática. 
Considerando a crise do Estado e o irrealismo de um Estado mínimo (proposta neoliberal), seu papel foi redefinido em 1995 com o Plano da Reforma do Aparelho do Estado (PDRAE), elaborado pelo Ministério da Administração Federal e Reforma do Estado (MARE,1995, p. 25), o qual abrangia três dimensões.

(1) a dimensão institucional-legal, relacionada aos obstáculos de ordem legal para o alcance de uma maior eficiência do aparelho do Estado;

(2) a dimensão cultural, definida pela coexistência de valores patrimonialistas e principalmente burocráticos com os novos valores gerenciais e modernos na administração pública brasileira; e

(3) a dimensão gerencial, associada às práticas administrativas.

O conjunto de medidas que alteravam o papel do Estado, sobretudo na forma de intervenção direta no domínio econômico, já vinham sendo empregadas desde o final da década de 1980, tendo como exemplo a Lei Federal 8.031/1990, que criou o Programa Nacional de Desestatização (PND), substituída pela Lei 9.491/1997. É importante destacar ainda que o programa de privatizações também foi estimulado pelo Consenso de Washington e pelas políticas neoliberais que já vinham sendo empregadas para reduzir a intervenção do Estado no ambiente econômico com a finalidade de desregulamentar setores econômicos e possibilitar superávit primários para fazer frente aos compromissos da dívida pública ${ }^{3}$.

A partir da relativa estabilidade econômica alcançada com o Plano Real, foi desencadeada a reforma do aparelho estatal, de forma esquemática, como mostra a figura 01 na sequência, abrangendo quatro setores: i) o núcleo estratégico, que define as leis e as políticas públicas,

As razões para a privatização, segundo Gremaud, Vasconcelos, Toneto Junior (2007), estão relacionadas à i) ineficiência das empresas públicas: baixa qualidade dos serviços e existência de déficits financeiros; ii) diminuição da capacidade estatal em fazer investimentos necessários como a ampliação dos serviços e atualização tecnológica das empresas; iii) necessidade de gerar receitas para se abater a elevada dívida estatal; iv) mudança no quadro tecnológico e financeiro internacional. 
cuja competência é do Estado, que espera que sejam cumpridas; ii) as atividades exclusivas, relacionadas à segurança, órgãos de regulamentação e fiscalização e ao sistema de seguridade social, que devem ser ofertados pelo Estado com qualidade e eficiência; iii) os serviços não exclusivos ou competitivos, cujas instituições não possuem o poder de Estado. os quais envolvem direitos humanos fundamentais, como educação e saúde, ou que possuem "economias externas". A propriedade ideal é a pública não-estatal por meio da publicização, e devem garantir qualidade e eficiência; iv) produção voltada ao mercado, que corresponde à área de atuação das empresas, caracterizada pelas atividades econômicas voltadas para o lucro, e a propriedade, via de regra, é privada (MARE, 1995, p. 41-43).

O Plano Diretor de Reforma do Aparelho do Estado (PDRAE) propõe para a administração pública uma combinação de princípios gerenciais e burocráticos. Para as atividades do núcleo estratégico, em que são necessárias segurança e efetividade, a proposta é um misto de ações gerenciais e burocráticas e, para os demais setores, uma administração pública gerencial, cujo requisito de eficiência é primordial.

Figura 01 - Setores do Estado, formas de propriedade e de administração

\begin{tabular}{|c|c|c|c|c|c|}
\hline & \multicolumn{2}{|c|}{ FORMA DE PROPRIEDADE } & \multicolumn{3}{|c|}{ FORMA DE ADMINISTRAÇÃO } \\
\hline & Estatal & $\begin{array}{l}\text { Pública } \\
\text { Não Estatal }\end{array}$ & Privada & Burocrática & Gerencial \\
\hline $\begin{array}{l}\text { NÚCLEO ESTRATÉGICO } \\
\text { Legislativo, Judiciário, } \\
\text { Presidência, Cúpula dos } \\
\text { Ministérios, Ministério Público }\end{array}$ & & & & & \\
\hline $\begin{array}{l}\text { ATIVIDADES EXCLUSIVAS } \\
\text { Regulamentação, Fiscalização, } \\
\text { Fomento, Segurança Pública, } \\
\text { Seguridade Social Básica }\end{array}$ & & & & & \\
\hline $\begin{array}{l}\text { SERVIÇOS NÃO } \\
\text { EXCLUSIVOS } \\
\text { Universidades, Hospitais, } \\
\text { Centros de Pesquisa, Museus }\end{array}$ & Publicização & & & & \\
\hline $\begin{array}{l}\text { PRODUÇÃO PARA O } \\
\text { MERCADO } \\
\text { Empresas Estatais }\end{array}$ & Privatização & & & & \\
\hline
\end{tabular}

Fonte: Plano Diretor da Reforma do Aparelho do Estado. MARE, 1995. p. 48. 
O programa de reforma do Estado tinha como objetivos garantir não apenas a propriedade e os contratos, mas também exercer seu papel complementar ao mercado na coordenação da economia; melhorar não apenas a organização e o pessoal do Estado, mas também suas finanças e todo o seu sistema institucional-legal; garantir a esse aparelho maior governança, ou seja, maior capacidade de governar e maior condição de implementar as leis e políticas públicas; tornar muito mais eficientes as atividades exclusivas de Estado, através da transformação das autarquias em "agências autônomas"; e tornar mais eficientes os serviços sociais competitivos ao transformá-los em organizações públicas não-estatais de um tipo especial: as "organizações sociais" (MARE, 1995, p. 41-43).

Contudo, em um balanço das reformas, Costa (2002), aponta que, por vários motivos, foi inconclusa e parcial, pois as medidas de reforma perderam dinamismo com o fracasso do Programa de Reestruturação e Qualidade dos Ministérios (PRQ), instituído em 1997, que visava à reestruturação organizacional dos ministérios e redução e racionalização de gastos, mas, como o programa era de adesão voluntária, poucos ministérios aderiram. As novas instituições que tinham por finalidade dar maior agilidade ao Estado e reduzir custos, como as agências executivas e as organizações sociais, pouco avançaram.

A agência executiva, que representa uma nova forma de organização da administração pública, é uma qualificação dada às autarquias ou fundações públicas que continuam a exercer atividades de competência exclusiva do Estado baseadas em agências autônomas. Para que uma instituição possa ser qualificada como agência executiva são exigidos alguns pré-requisitos, como: plano estratégico de reestruturação e desenvolvimento institucional e definição de indicadores de desempenho e um contrato de gestão, conforme previsão do artigo $1^{\circ}, \S 1^{\circ}$, do Decreto 2.487 de 1998.

Entretanto, há significativas dificuldades de implementação de agências executivas, o que, segundo Bresser-Pereira (1998a), é decorrente da falta de integração entre as diversas áreas das instituições, que não atuam de forma coordenada e muitas vezes se veem como 
rivais. Outro problema é a falta de comunicação entre as instituições. Basicamente, a percepção é a de que a manutenção das tarefas/ atividades sem uma adequada integração ou coordenação é uma forma de manter os poderes e espaços conquistados. Portanto, o interesse em preservar espaços de poder age no sentido de manter o status quo, sem aceitar as inovações trazidas pelo PDRAE.

As agências reguladoras tiveram maior destaque, porque dizem respeito às reformas nas atividades exclusivas do Estado, o que culminou por promover, segundo Bresser-Pereira e Pacheco (2005, p. 5), a agencification: "constituição de agências movidas por finalidades específicas, separadas dos ministérios e departamentos formuladores de políticas, a eles conectados por meio de acordos prévios de resultados a atingir".

Com o programa de privatização, os serviços públicos privatizados passam a ser fiscalizados e regulados pelas agências reguladoras, que podem "ser entendidas como uma espécie de agência executiva, dotada de autonomia maior, uma vez que a administração deve seguir princípios muito semelhantes" segundo Bresser-Pereira (1998a, p. 226), mas que devem ser tratadas de forma independente, pois são instituídas por lei, e não por delegação do Presidente da República. As primeiras agências reguladoras independentes, sob forma de autarquia, foram criadas a partir da segunda metade dos anos 1990, com a finalidade de atender as determinações da Constituição de 1988. Atualmente, no âmbito do governo federal, há 10 agências reguladoras instituídas no Paíse outra está em análise no Congresso Nacional, a Agência Nacional de Mineração (ANM) (PL 5.807/2013).

Contudo, as agências reguladoras, segundo Carvalho (2011, p. 76), permanecem com problemas "com respeito à definição do seu grau de autonomia frente ao governo e aos interesses econômicos regulados, bem como à sua real capacidade de atuação, em virtude da insuficiência de quadros técnicos qualificados", problemas esses que geram instabilidade nos marcos regulatórios, dificultando avanços na prestação de serviços bem como a ampliação de investimentos por parte da iniciativa privada. 
Em relação às organizações sociais, a proposta era transformar em entidades públicas não estatais os serviços sociais e científicos, o que abrange as áreas de ensino, pesquisa científica, desenvolvimento tecnológico, preservação e proteção do meio ambiente, saúde e cultura em que o Estado atua diretamente, conforme estabelece a Lei n. 9.637/1998, ou seja, em entidades do terceiro setor, sem fins lucrativos, qualificadas como organizações sociais. Entretanto, há ainda resistências para criação de organizações sociais, principalmente na área de ensino. Segundo Rezende (2002, p. 113), "as reformas gerenciais não têm encontrado cooperação 'espontânea' dos atores para criarem uma cultura burocrática orientada pelo desempenho", pois podem implicar em perdas sobre o controle de instituições em relação aos orçamentos e recursos humanos, ou seja, conflitos na distribuição de poderes.

A preocupação central na reforma do Estado, segundo BresserPereira (1998a), deve estar em criar condições para o fortalecimento do Estado e as mudanças na gestão pública não devem ter como objetivo precípuo a redução do seu tamanho enquanto orçamento, mas garantir condições do pleno atendimento aos direitos à cidadania, fortalecer o regime democrático e as instituições.

Muito embora as reformas do Estado e a reforma gerencial tenham contribuído para alguns avanços na gestão pública, solucionando problemas de ordem social, política e econômica que, associados à estabilidade econômica, proporcionaram uma melhora nos indicadores de desenvolvimento socioeconômico, conforme destaca Motta (2007, p. 26), ainda há marcas do tradicionalismo brasileiro, "sobretudo o patrimonialismo e o elitismo, ainda presentes em muitas práticas administrativas". As marcas da herança do passado e da cultura colonialista não foram ainda plenamente apagadas, inclusive no âmbito da administração pública ${ }^{4}$, o que torna o desafio ainda mais complexo

4 Para melhor compreensão das questões da cultura da burocracia brasileira, ver: Faoro (2001) e Carvalho (1997, p. 229-250). 
para se alcançar uma administração pública gerencial, fundada na eficiência dos serviços públicos, na avaliação de desempenho e no controle de resultados.

\section{A crise financeira de 2008: medidas econômicas e políticas}

A crise financeira internacional de 2008 teve origem no mercado norte-americano de hipotecas de alto risco, que atingiu de alguma forma a dinâmica econômica de países desenvolvidos ou em desenvolvimento, mas que ainda há rescaldos, pois não foi plenamente restabelecidos às capacidades de investimentos. Esta crise é considerada a mais grave experimentada pela economia mundial nos últimos 80 anos, pois, embora tenha sido originada no setor financeiro, acabou por se estender à esfera produtiva por meio da restrição de acesso ao crédito, modificação de políticas bancárias, dentre outros aspectos, o que exigiu medidas anticíclicas dos governos para mitigar os impactos recessivos sobre a economia.

No Brasil, para reduzir os efeitos da crise no sistema financeiro nacional, foi editada a Medida Provisória 443 (que posteriormente foi convertida na Lei n 11.908/2009) que permitiu ao Banco do Brasil e Caixa Econômica Federal a aquisição de ações de instituições financeiras privadas sem nem mesmo haver licitação ${ }^{5}$ (BRASIL, 2009a). A reação do BNDES, segundo Coutinho (2011, p.412), "foi acelerar os desembolsos do Banco e acelerar a aprovação de projetos, e lutar intensamente para que o Banco pudesse executar um orçamento em expansão, de modo a conseguir no último trimestre de 2008 contrabalançar minimamente a escassez de crédito". A ação do BNDES foi no sentido de possibilitar uma política anticíclica, garantindo projetos já contratados e estimulando novos investimentos que pudessem manter a economia aquecida,

5 Essa mesma lei também autoriza, em seu artigo $7^{\circ}$, a União a conceder crédito ao BNDES (Banco Nacional de Desenvolvimento Econômico e Social) no valor de até R\$3.000.000.000,00 (três bilhões de reais), para ser utilizado na abertura de linhas de crédito para capital de giro das empresas contratadas pelos governos federal, estaduais ou municipais, para execução de obras de infraestrutura no âmbito do PAC - Programa de Aceleração do Crescimento (BRASIL, 2009a). 
com manutenção também dos postos de trabalho que foram, em outros países, duramente afetados, a exemplo de Portugal e Espanha. Conforme dados do Eurostat (2016), a taxa de desemprego em Portugal era $8,8 \%$ em 2008, aumentando para 16,4\% em 2013; na Espanha, o desemprego saltou de $11,3 \%$ para $26,1 \%$ no mesmo período. No Brasil, conforme dados do IBGE (2016), a taxa de desemprego foi de 7,9\% em 2008 e 5,4\% em 2013. A política de estímulos anticíclicos garantiu, em um curto prazo, uma redução no nível de desemprego.

Além das medidas para o sistema financeiro e acesso ao crédito, o governo adotou medidas de caráter tributário, como a redução do Imposto sobre Produtos Industrializados ( IPI) e a Contribuição para Financiamento daSeguridade Social(COFINS), para estimularo consumo e mitigar os reflexos da crise sobre a atividade produtiva, principalmente nos setores automobilístico, de eletrodomésticos da chamada linha branca e no setor de materiais de construção, ou seja, uma intervenção do Estado sobre a economia por meio da extrafiscalidade. Entretanto, Vosgerau e Gonçalves (2013, p. 218) destacam que a política pública de redução de IPI para estimular o crescimento econômico não trouxe os resultados esperados, pois o Brasil apresentou um crescimento menor que a média mundial em 2012 e o pior entre os países do BRICs (Brasil, Rússia, China e África do Sul), "o que leva a crer que, se a redução do IPI efetivamente teve algum impacto no crescimento da economia, ele foi muito pequeno, o que parece não justificar as demais consequências negativas que a redução trouxe consigo", especialmente a partir de 2014.

As medidas para enfrentar a crise demonstram uma preocupação do governo em manter a capacidade de demanda com políticas de estímulo ao consumo, que, associadas à solidez macroeconômica proporcionada pelo câmbio flutuante, ao considerável volume de reservas externas, à dívida externa desdolarizada, à inflação sob controle, ao superávit primário e menor alavancagem no sistema financeiro, reduziu a exposição do sistema financeiro nacional à crise internacional, ao menos em um primeiro momento. O padrão de comportamento do Produto Interno Bruto brasileiro no período de 2008 a 2015 foi bastante instável, 
com um crescimento real, em 2008, de 5,1\%, e queda em $2009(-0,1 \%)$. Já em 2010 houve uma recuperação significativa, aumento de 7,5\%, mas, nos anos seguintes(2011 a 2014), houve uma redução no ritmo de crescimento do PIB, com 3,9\%, 1,9\%, 3\% e 0,1\% respectivamente (IBGE, 2016b). Esses dados demonstram que o Brasil conseguiu uma relativa estabilidade enquanto os preços das commodities exportadas estavam altos, mas, a partir de 2013, quando os preços começaram a cair, surgiram os primeiros sinais de uma crise mais severa à economia nacional.

O PIB de 2015 teve uma retração de $-3,8 \%$, o que indica que o modelo econômico, pautado na sustentação do consumo, não trouxe estabilidade e crescimento econômico conforme o esperado. A crise atual que o país enfrenta é reflexo das medidas econômicas adotadas para o enfretamento da crise de 2008 , como também pela falta de medidas para estimular a competitividade industrial e, principalmente, pelo não ajuste da estrutura do Estado, como redução de funções que poderiam ser desempenhas pela iniciativa privada e dos custos associados à manutenção da burocracia estatal.

A capacidade em resolver os problemas "macroeconômicos de curto prazo - estabilização econômica e governabilidade orçamentária", no primeiro governo Lula, segundo Carvalho (2011, p. 78), proporcionou a inclusão da gestão na Agenda Nacional de Desenvolvimento como preocupação de longo prazo, com foco na redução das desigualdades, diante do diagnóstico da insuficiência das ações do Estado e do dilema quantidade versus qualidade no segundo governo Lula.

No âmbito da gestão pública, foi elaborada a Agenda Nacional de Gestão Pública em 2009, segundo Carvalho (2011), com vistas à modernização, com o emprego de tecnologias de informação para promover a integração dos diversos órgãos do governo, de modo a modificar o modus operandi herdado pelas organizações públicas, para possibilitar melhor coordenação entre as esferas de governo. Essa agenda se propôs a debater seis eixos temáticos: burocracia profissional e meritocracia; qualidade da política pública; pluralismo institucional; 
repactuação federativa nas políticas públicas; papel dos órgãos de controle, e governabilidade; apresentando os problemas, soluções e desafios para cada um deles.

Sobre a primeira temática, burocracia profissional e meritocracia, foram identificados como problemas: a heterogeneidade e complexidade da administração pública, em que o processo de profissionalização da burocracia ainda não se completou; profissionalização e mérito no serviço público; política remuneratória; capacitação para competências; ocupação de cargos de confiança e organização da administração pública. Como solução, apresentou-se a necessidade de incluir a gestão pública no conjunto de ações para melhoria dos serviços públicos; organizar e consolidar a política de carreira; recuperar a imagem da burocracia junto à sociedade; ter critérios transparentes para cargos de confiança, promoção à competência e qualificação (BRASIL, 2009b). Contudo, conforme apontam os autores, ainda há resistências ideológicas, corporativismo e a rigidez da estrutura legal, que impede a implementação de inovações na política de recursos humanos.

Em relação à estrutura do funcionalismo público, houve a realização de diversos concursos públicos para, em parte, substituir pessoal terceirizado, bem como atender demandas de servidores especializados em agências reguladoras e no ensino superior. O Boletim Estatístico de Pessoal e Informações Organizacionais, do Ministério do Planejamento, aponta que o número de funcionários civis ativos vinculados ao Poder Executivo no governo federal em dezembro de 2002 era de 485.741 e aumentou para 567.808 em 2010. Atualmente, conforme dados de julho de 2015 , o número de funcionários é de 618.441 , o que representa um aumento líquido (ingressos menos aposentadorias e demais exclusões), durante o governo Lula (2002-2010), de 82.067 funcionários, e, no governo Dilma, de 50.633 (2011-2015) (BRASIL, 2015).

Além da realização de concursos públicos e contratação de funcionários, o governo promoveu reajustes reais de salário e a criação de novas carreiras e cargos, mas, segundo Novelli (2011), não há elementos suficientes que permitam afirmar que os governos Lula 
(2002-2010) incorporaram o diagnóstico e o prognóstico do PDRAE, dado que um dos setores que teve maior contratação foi o setor de educação ${ }^{6}$, setor considerado não exclusivo do Estado. Todavia, as carreiras e cargos que obtiveram privilégios em relação à remuneração estão vinculados ao núcleo estratégico e aos serviços exclusivos, como estabelecido pelo PDRAE.

Assim, de um lado, o governo ampliou os gastos da Administração Pública, principalmente em custeio, mas, por outro lado, houve perda de capacidade em investimentos, levando o governo a ampliar esforços, de forma tardia, além de morosa, para captar investimentos privados por meio de concessões de serviços públicos em setores estratégicos de infraestrutura, visando manter o nível de crescimento e competitividade econômica do país.

\subsection{A crise financeira de 2008 e a burocracia}

Nesse sentido, a crise de 2008 suscitou o debate em diferentes espaços da sociedade sobre o papel do Estado, tendo, segundo BresserPereira (2010, p. 70), como principal tarefa "restaurar o poder regulador do Estado de maneira a permitir que os mercados cumpram sua função de coordenação econômica", pois, segundo o autor:

[...] o capitalismo moderno exige não desregulação,mas regulação; que a regulação não impede, mas permite acoordenação da economia pelo mercado; que quanto mais complexauma economia nacional, mais regulada precisa ser se desejarmos nosbeneficiar das vantagens da alocação ou coordenação de recursos pelomercado; que a política econômica deve estimular o investimento emanter a economia estável, não ajustarse a princípios ideológicos; e que o sistema financeiro deve financiar investimentos produtivos,não alimentar a especulação (BRESSERPEREIRA, 2010, p. 70).

6 De acordo com o Boletim Estatístico de Pessoal e informações organizacionais, o Ministério da Educação tinha, em dezembro de 2002, 165.163 servidores; em dezembro de 2010 eram 215.025 e, segundo os dados de julho de 2015, são 275.727 . No período do governo Lula houve um aumento de $23,18 \%$ e, no governo Dilma, um aumento de $22,01 \%$. 
De modo semelhante, Herbst e Duarte (2013, p. 25) apontam que a crise de 2008 tornou "explícita e urgente a necessidade de se criar uma regulação para prevenir crises, ao invés de apenas remediá-las". Essa crise, segundo os autores, pode marcar o "fim da ditadura dos mercados e o fortalecimento do Estado será o meio mais eficiente para providenciar tais correções ao sistema capitalista - visto que o Estado tem, por sua própria natureza, responsabilidades morais e sociais que as empresas não têm". Para Bresser-Pereira e Pacheco (2005, p. 1), a regulação e a intervenção do Estado na economia devem atender aos interesses da sociedade, principalmente nas situações de perda de bem-estar, combatendo as falhas de mercado. Assim, a reforma do Estado deve conduzir para o fortalecimento, tanto do Estado, dotado de legitimidade política para fazer frente a eventuais crises econômicas, como das instituições.

A crise econômico-financeira de 2008 estimulou uma maior participação do Estado como indutor do desenvolvimento, instituindo programas para manter a capacidade de demanda interna, estímulos às atividades produtivas, como a Política de Desenvolvimento Produtivo (PDP), lançada em maio de 2008, e a manutenção do Programa de Aceleração do Crescimento (PAC). Contudo, o governo não deu a devida atenção às políticas de concessão de bens públicos à iniciativa privada, principalmente no setor de infraestrutura, e, segundo Fábio Giambiagi em entrevista à Folha de São Paulo (2015), o governo demorou em prosseguir com os programas de privatização e concessões:

Durante muito tempo houve uma espécie de veto ideológico porque concessão, por assim dizer, 'cheirava' a privatização e não se avançava [...] No primeiro governo Dilma houve certa paralisia e agora, finalmente, deslancharam algumas atividades. Tivemos leilões importantes, principalmente em aeroportos e rodovias. A única crítica que cabe a isso é ter vindo com dez anos de atraso.

Com a estratégia de concessões de infraestrutura, o governo federal reduz a sua participação direta do Estado nas atividades econômicas e busca atrair investimentos privados, tanto que, entre 2007 e 2009, 
foram realizadas concessões de rodovias federais, e as concessões de rodovias de aeroportos entre 2009 e 2013. No período entre 2007 e 2014 houve significativos investimentos privados na infraestrutura de rodovias, conforme dados da Associação Brasileira de Concessionárias de Rodovias (ABCR) (2016). Em 2007, foram aplicados R\$ 1,4 bilhões; em 2009, investidos R\$ 3 bilhões; e, em 2014, o valor atingiu $R \$ 6,9$ bilhões.

A Infraero iniciou em 2012 o programa de concessões de aeroportos. O primeiro lote de concessões contemplou o Aeroporto Internacional Presidente Juscelino Kubitschek, em Brasília, que foi arrematado por R $\$ 4.501$ bilhões e por um prazo de 25 anos; o Aeroporto Internacional de São Paulo-Guarulhos - Governador André Franco Montoro, foi arrematado por $\mathrm{R} \$ 16.213$ bilhões e pelo prazo de 20 anos; e o Aeroporto Internacional de Viracopos, em Campinas, foi arrematado por R 3.821 bilhões, pelo prazo de 30 anos. O segundo lote das concessões contemplou o Aeroporto Internacional do Rio de JaneiroGaleão - Antônio Carlos Jobim, que recebeu um lance de R\$ 19 bilhões para operar o aeroporto por 25 anos, e o Aeroporto Internacional de Belo Horizonte-Confins - Tancredo Neves, arrematado por R\$1,8 bilhão para ser operado por 30 anos (INFRAERO, 2016).

Em continuidade ao programa de concessões para modernizar parte da infraestrutura de transportes, o governo lançou, em junho de 2015, a segunda etapa do Programa de Investimentos em Logística, abrangendo rodovias, ferrovias, aeroportos e portos. Nesse sentido, as medidas tomadas estão de acordo com as estratégias do Plano da Reforma do Aparelho do Estado (PDRAE) de 1995. Com as concessões, as agências reguladoras devem fazer o acompanhamento e a fiscalização dos contratos.

As transformações instituídas pelo PDRAE e pela Emenda Constitucional n. 19 ainda não foram suficientes para promover uma administração pública com uma cultura gerencial. As medidas de "reversão à terceirização", principalmente aquelas que visam contratar pessoal de nível médio, e a política salarial têm sido um retrocesso 
para a administração pública burocrática segundo Bresser-Pereira e Pacheco (2005, p. 11). Problemas como a transparência para a ocupação de cargos comissionados no serviço público e a Lei Orgânica da Administração Pública Federal ${ }^{7}$ também ainda não foram sanados, o que contribui para a burocracia não contribuir para o processo de superação da crise atual.

Para além dos problemas destacados por Bresser-Pereira e Pacheco (2005), o governo, por uma ideologia, perdeu uma significativa oportunidade política e econômica em expandir de forma significativa os investimentos nos segmentos de infraestrutura pesada por meio da política de concessões e privatizações. Como também poderia ter desempenhado mudanças no arcabouço institucional para aprofundar os mecanismos de gestão da burocracia gerencial e profissional nos diversos setores da administração pública, especialmente nas agências reguladoras.

\subsection{A burocracia no ambiente de negócios}

A burocracia é considerada um dos maiores obstáculos para o crescimento econômico no ambiente dos negócios. Segundo o relatório Burocracia: custos econômicos e propostas de combate, da Federação das Indústrias do Estado de São Paulo (FIESP) (2015), a burocracia implica em prejuízos para os cidadãos e empresários, pois "excessivos processos de controles e exigências provocam aumentos de custos e reduzem os benefícios dos bens e serviços oferecidos".

No ranking internacional Doing business (2015), do Banco Mundial, a economia brasileira, num rol de 189 economias, encontrase na $120^{a}$ posição na classificação de facilidade de fazer negócios, melhorando três posições, quando comparada ao ano de 2014, o que já

A Portaria $n^{\circ} 426$, de 6 de dezembro de 2007, do Ministério do Planejamento, Orçamento e Gestão, instituiu a comissão para elaborar anteprojeto de Lei Orgânica da Administração Pública Federal, que se propõe a substituir o Decreto-Lei n 200/1967, no que se refere à definição de entidades que compõem a administração direta e indireta. Embora o anteprojeto de lei tenha sido entregue pela comissão em 16 de julho de 2009, segue ainda em fase de discussão pública. 
permite avaliar a situação do Brasil na temática da burocracia no cenário internacional.

Para reduzir a burocracia nas atividades econômicas, o governo lançou o Programa Bem Mais Simples Brasil, por meio do Decreto $\mathrm{n}^{\circ}$ 8.414, de 26 de fevereiro de 2015, cujo objetivo é promover a simplificação do acesso ao cidadão, empresas e entidades sem fins lucrativos, dos serviços e informações públicas, promover a prestação de informações e serviços por meio eletrônico, reduzir formalidades e exigências, promover a integração dos sistemas de informações e modernizar a gestão interna da administração pública.

O Programa Bem Mais Simples Brasil prevê medidas para facilitar a abertura e fechamento de empresas, com a unificação de cadastros e agrupamento de serviços públicos, com a possibilidade de baixa de empresa através da internet, no Portal Empresa Simples, sem a exigência das certidões negativas de débitos tributários, previdenciários e trabalhistas nas juntas comerciais, que era uma das propostas de redução da burocracia nos negócios apresentada pela FIESP em 2010 (PORTAL BRASIL, 2015).

Programa Bem Mais Simples Brasil, segundo Barbosa (2015, p. 22), "é uma tentativa política de acelerar a simplificação e a desburocratização dos serviços públicos, com ênfase na atividade empresarial e no procedimento de abertura e fechamento de empresas", que vem para contribuir na efetiva implantação da Rede Nacional para a Simplificação do Registro e da Legalização de Empresas e Negócios (Redesim), com a informatização da prestação de serviços públicos. Contudo, conforme destaca o autor, "constata-se que o sistema brasileiro poderia ser aprimorado", inspirando-se em outros modelos, como o sistema do Chile, líder no ranking na América do Sul em informatização do procedimento de abertura de empresas.

Apesar das medidas tomadas para melhorar os indicadores de abertura e fechamento de negócios no Brasil, o relatório do Banco Mundial, Doing business 2016, indicou uma piora de cinco posições no ranking do país. Para formar o ranking, são avaliados dez tópicos, 
dos quais houve piora em sete (abertura de empresas, obtenção de alvarás de construção, obtenção de crédito, proteção dos investidores minoritários, pagamento de impostos, resolução de insolvência e registros de propriedades), um ficou estável (execução de contratos), e somente dois (obtenção de eletricidade e comércio internacional) apresentaram melhoras (DOING BUSINESS, 2016).

Com esse indicador é possível afirmar que, no âmbito dos negócios, a situação de crise política e econômica pela qual o país passa, apesar de medidas adotadas, elevou o nível de burocracia para o ambiente empresarial, o que implica dificuldades em atrair novos investimentos. Isto, por sua vez, provoca uma restrição ao desenvolvimento nacional, decorrente das dificuldades burocráticas que impõe mais obstáculos à atividade econômica.

\section{Conclusão}

A crise do Estado, que se estendeu durante as décadas de 1980 e 1990, mostrou ser necessário promover uma reforma do Estado para modificar o modelo intervencionista desenvolvimentista para um modelo social-liberal, com a implementação de uma reforma, ainda que incompleta, do próprio Estado e da administração pública. O Plano Diretor da Reforma do Aparelho do Estado, principal documento das mudanças da organização da gestão pública, proporcionou avanços na administração pública burocrática brasileira na direção de uma burocracia gerencial e profissional, ainda que remanesçam marcas do patrimonialismo e do clientelismo em muitas práticas da administração pública, tal como visto e é de conhecimento notório, na chamada Operação Lava-Jato [sic], em que ficam claros o clientelismo e as relações espúrias entre os interesses privado e público.

Com a crise financeira de 2008, ampliaram-se as intervenções do Estado na economia com a adoção de medidas para estimular o crescimento econômico, como redução da taxa de juros, facilitação de acesso a crédito, redução de alíquotas de impostos, diferentes das 
medidas restritivas que foram empregadas nas décadas de 1980 e 1990. Mas, considerando as dificuldades de investimentos em infraestrutura, fez-se necessário que o governo timidamente prosseguisse em medidas de concessão de serviços públicos, principalmente na logística de transportes, em consonância com o PDRAE, com o objetivo de ampliar e dinamizar a oferta de serviços públicos que passaram a ser fiscalizados pelas agências reguladoras, mas que, diante do quadro político e econômico, poderia ter sido aprofundado significativamente, garantindo maiores investimentos e maior competitividade.

Em relação ao funcionalismo público federal, apesar da realização de diversos concursos públicos para, em parte, substituir pessoal terceirizado e atender demandas de servidores especializados, como agências reguladoras do ensino superior, não houve uma efetiva alteração em direção à burocracia gerencial e profissional, especialmente porque foram mantidos muitos cargos em confiança que acabam por politizar o processo de escolha e nomeação destes funcionários, tornando em parte ineficientesos concursos públicos.

No ambiente de negócios, a percepção constatada pelo relatório Doing Business foi de que houve uma piora das condições para se fazer negócios no Brasil, uma vez que a posição brasileira no ranking internacional caiu cinco posições, indicando que não houve avanço na redução do sistema burocrático para quem almeja realizar investimentos no país.

As medidas tomadas pelos formuladores de políticas públicas ainda não são suficientes para uma mudança da cultura burocrática brasileira, inclusive por oscilações na condução de reformas que possam conduzir a administração pública à burocracia gerencial. Ainda há marcas e ações da cultura burocrática patrimonialista e clientelista brasileira, que não se amoldam à burocracia gerencial, mais impessoal e profissionalizada, voltada principalmente para uma boa execução dos serviços públicos inerentes à sua condição.

Desse modo, conclui-se com este trabalho que as reformas na administração pública ainda não são suficientes para modificar a 
burocracia estatal de forma que permita investimentos no país e garantir uma maior eficiência dos serviços públicos prestados, de tal forma que tais aspectos negativos sejam ressalvados em momentos de crise, razão pela qual se deve continuar as reformas necessárias para fortalecer o papel do Estado para que se possam preservar os direitos dos cidadãos.

\section{Referências}

ASSOCIAÇÃO BRASILEIRA DE CONCESSIONÁRIAS DE RODOVIAS - ABCR. Dados financeiros. Disponível em: <http://www.abcr.org. $\mathrm{br} /$ Conteudo/Secao/42/dados+financeiros.aspx>. Acesso em: 06 jan. 2016.

BARBOSA, L. G. O que é o "Bem Mais Simples Brasil"? Brasília: Núcleo de Estudos e Pesquisas/Senado, 2015. (Texto para Discussão $n^{\circ}$ 178). Disponível em: <www.senado.leg.br/estudos>. Acesso em: 2 jul. 2015

BRASIL. Lei $\mathbf{n}^{0}$ 11.908, de 03 de março de 2009. Disponível em: <http://www.planalto.gov.br/ccivil_03/_ato2007-2010/2009/lei//11908. htm>. Acesso em: 30 jul. 2015.

BRASIL. Secretaria de Assuntos Estratégicos (SAE). Agenda Nacional de Gestão Pública. Brasília: Imprensa Nacional, 2009b. Disponível em: <http://www.planejamento.gov.br/marcella/segep/ comunicados/091207_seges_agenda_gestao.pdf>. Acesso em: 19 jul. 2015.

BRASIL. Ministério do Planejamento, Orçamento e Gestão. Boletim Estatístico do Pessoal, Brasília, n. 232, ago. 2015. Disponível em: <http://www.planejamento.gov.br/secretarias/upload/Arquivos/servidor/ publicacoes/boletim_estatistico_pessoal/2015/151214_bol232_ ago2015_parte_i.pdf >. Acesso em: $21 \mathrm{dez} .2015$.

BRASIL. Ministério do Planejamento, Orçamento e Gestão. Governo lança segunda etapa do Programa de Investimento em Logística. Disponível em: < http://www.planejamento.gov.br/assuntos/programade-investimento-em-logistica-pil/noticias/governo-lanca-segunda- 
etapa-do-programa-de-investimento-em-logistica>. Acesso em: 18 jul. 2015.

BRASIL. Ministério da Administração Federal e Reforma do Estado MARE. Plano diretor da reforma do aparelho do estado. Brasília, 1995.

BRESSER-PEREIRA, Luiz Carlos. Reforma do Estado para a cidadania: a reforma gerencial na perspectiva internacional. São Paulo: Editora 34, 1998a.

BRESSER-PEREIRA, Luiz Carlos. Uma reforma gerencial da Administração Pública no Brasil. Revista do Serviço Público, Brasília, v. 49, n. 1, p. 5-42, jan./mar. 1998b.

BRESSER-PEREIRA, Luiz Carlos. Da administração pública burocrática à gerencial. In: BRESSER-PEREIRA, Luiz Carlos; SPINK, Peter (Org.). Reforma do Estado e administração pública gerencial. Rio de Janeiro: Fundação Getúlio Vargas, 1998c.

BRESSER-PEREIRA, Luiz Carlos. A crise financeira global e depois: um novo capitalismo? Novos Estudos - Centro Brasileiro de Análise e Planejamento - CEBRAP, São Paulo, n. 86, p. 51-72, mar. 2010.

BRESSER-PEREIRA, Luiz Carlos; PACHECO, Regina Silvia. A reforma do estado brasileiro e o desenvolvimento. Revista Eletrônica sobre a Reforma do Estado, Salvador, n. 3, p. 1-18, set./out./nov. 2005. Disponível em: <http://direitodoestado.com/revista/RERE-3SETEMBRO-2005-BRESSER.pdf>. Acesso em: 06 jul. 2015.

CARVALHO, Eneuton Dornellas Pessoa de. O aparelho administrativo Brasileiro: sua gestão e seus servidores - de 1930 aos dias atuais. In: CARDOSO JUNIOR, José Celso (Org.). Burocracia e ocupação no setor público brasileiro. Rio de Janeiro: Ipea, 2011. p. 47-89.

COHN, Gabriel (Org.); FERNANDES, Florestan (Coord.). Max Weber: sociologia. São Paulo: Ática, 2003.

COSTA, Valeriano Mendes Ferreira. A dinâmica institucional da reforma do Estado: um balanço do período FHC. In: ABRUCIO, Fernando Luiz; LOUREIRO, Maria Rita (Org.). O Estado numa era de reformas: os anos FHC - Parte 2. Brasília: MP, Seges, 2002. p. 9-57. 
COUTINHO, Luciano. Cadernos do Desenvolvimento. Entrevista. Rio de Janeiro, v. 6, n. 9, p. 406-419, jul./dez. 2011. Disponível em: $<$ http://anteriores.cadernosdodesenvolvimento.org.br/wp-content/ uploads/2011/10/CD9_entrevista1.pdf.> Acesso em: 08 jul.2015.

CROZIER, Michel. O fenômeno burocrático: ensaio sobre as tendências burocráticas dos sistemas de organização modernos e suas relações, na França, com o sistema social de cultural. Tradução de Juan A. Gilli Sobrinho. Brasília. Universidade de Brasília, 1981. p. 305-339.

DINIZ, Eli. Globalização, reforma do estado e teoria democrática contemporânea. São Paulo em perspectiva, São Paulo, v. 15 n. 4, p.14-22, out./dez. 2001. Disponível em:<http://www.scielo.br/pdf/spp/ v15n4/10368.pdf>. Acesso em: 17 jul. 2015.

DOING BUSINESS 2015. Disponível em: <http://portugues. doingbusiness.org/data/exploreeconomies/brazil>. Acesso em: 18 jul. 2015.

DOING BUSINESS 2016. Disponível em: <http://portugues. doingbusiness.org/data/exploreeconomies/brazil\#close>. Acesso em: 08 jan. 2016.

EMPRESA BRASILEIRA DE INFRAESTRUTURA AEROPORTUÁRIA INFRAERO. Concessão de aeroportos. Disponível em: <http://www. infraero.gov.br/index.php/br/concessoes.html>. Acesso em: 07 jan. 2016.

EUROSTAT. Employment and unemployment. Disponível em: <http://ec.europa.eu/eurostat/en/web/lfs/data/database>. Acesso em: 06 jan. 2016.

FEDERAÇÃO DAS INDÚSTRIAS DO ESTADO DE SÃO PAULO FIESP. Relatório Burocracia: custos econômicos e propostas de combate. São Paulo, 2010. Disponível em: <http://www.fiesp. com.br/indices-pesquisas-e-publicacoes/relatorio-burocracia-custoseconomicos-e-propostas-de-combate/>. Acesso em: 31 jul. 2015.

GABARDO, Emerson. Interesse público e subsidiariedade: o Estado e a sociedade civil para além do bem e do mal. Belo Horizonte: Fórum, 2009. p 109-123. 
GERTH, Hans H.; MILLS, Charles Wright. Max Weber: ensaios de sociologia. Tradução de Waltensir Dutra. Rio de Janeiro: Guanabara, 1946.

GREMAUD, Amaury Patrick; VASCONCELOS, Marco Antonio Sandoval; TONETO JÚNIOR, Rudinei. Economia brasileira contemporânea. 7. ed. São Paulo: Atlas, 2007.

HERBST, Kharen Kelm; DUARTE, Francisco Carlos. A nova regulação do sistema financeiro face à crise econômica mundial de 2008.

Revista de Direito Econômico e Socioambiental, Curitiba, v. 4, n. 2, p. 16-38, jul./dez. 2013.

INSTITUTO BRASILEIRO DE GEOGRAFIA E ESTATÍSTICA - IBGE. Pesquisa mensal de emprego. Disponível em: <http://www.ibge. gov.br/home/estatistica/indicadores/trabalhoerendimento/pme_nova/ defaulttab_hist.shtm>. Acesso em: 06 jan. 2016.

INSTITUTO BRASILEIRO DE GEOGRAFIA E ESTATÍSTICA - IBGE. Contas nacionais trimestrais. Disponível em: <http://www.ibge.gov. $\mathrm{br} /$ home/estatistica/indicadores/pib/defaultcnt.shtm>. Acesso em: 07 jan. 2016b.

LEFORT, Claude. O que é Burocracia? In: CARDOSO, F. H.; MARTINS, C. E. (Org.). Política \& sociedade. São Paulo: Nacional, 1979. p. $148-159$.

MOTTA, Paulo Roberto. Dificuldades e possibilidades da administração pública nos últimos 70 anos. Revista do Serviço Público, Brasília, ed. esp., p. 19-27, 2007.

NOVELLI, José Marcos Nayme. Estado, administração e burocracia pública no brasil (1995-2009). Crítica e Sociedade: revista de cultura política, Uberlândia, v.1, n.1, p. 124-138, jan./jun. 2011.

PARA economista, concessões chegam tarde e 'operam por surtos' no Brasil. Folha de São Paulo, São Paulo, 23 jun. 2015. Disponível em: < http://www1.folha.uol.com.br/multimidia/videocasts/2015/06/1646508para-economista-concessoes-chegam-tarde-e-operam-por-surtos-nobrasil.shtml>. Acesso em: 16 jul. 2015. 
PORTAL BRASIL. Programa Bem Mais Simples: menos burocracia no ambiente de negócios. Disponível em: <http://www.brasil.gov.br/ economia-e-emprego/2015/04/programa-bem-mais-simples-menosburocracia-no-ambiente-de-negocios>. Acesso em: 07 jan. 2016.

REZENDE, Flávio da Cunha. Razões da crise de implementação do estado gerencial: desempenho versus ajuste fiscal. Revista de Sociologia e Política, Curitiba, n. 19, p. 111-121, nov. 2002.

VOSGERAU, Douglas; GONÇALVES, Oksandro. A extrafiscalidade como política pública de intervenção do estado na economia e desenvolvimento: o ICMS ecológico e o IPI de veículos automotores.

Ciências Sociais Aplicadas em Revista, Marechal Cândido Rondon, Cascavel, v. 13, n. 24, p. 207-221, 2013.

WEBER, Max. Economia e sociedade: fundamentos de uma sociologia compreensiva. Tradução de Regis Barbosa e Karen Elsabe Barbosa. Brasília: UNB, 1999.

Recebido em: 17/06/2016

Aprovado em: 27/10/2016 